\title{
Are we underestimating the cardiovascular risks of seafarers?
}

\section{Richard Pougnet ${ }^{1,2}$, Laurence Pougnet ${ }^{1,2}$, David Lucas ${ }^{1}$, Jean-Dominique Dewitte ${ }^{1,2}$, Brice Loddé ${ }^{1,2}$}

\author{
${ }^{1}$ French Society of Maritime Medicine (Société Française de Médecine Maritime [SFMM]), Brest, France
}

${ }^{2}$ Université de Bretagne Occidentale, Brest, France

In early 2019, France changed the recommendations on alcohol consumption. The key message is to reduce alcohol consumption because even a small consumption leads to health risks. The National Institute of Public Health "Santé Publique France" currently recommends to avoid consuming more than 2 glasses a day, 10 per week, and to ensure to have days of abstinence every week (Santé Publique France. Avis d'expert relatif à l'évolution du discours public en matière de consommation d'alcool en France. 2019 https://www.santepubliquefrance.fr/les-actualites/2017/avis-d-experts-relatif-al-evolution-du-discours-public-en-matiere-de-consommation-dalcool-en-france-organise-par-sante-publique-france-et-l-insti).

Other countries had also re-evaluated their public health policy in previous years, such as Australia in 2009, Canada in 2011 and the United Kingdom in 2016. These countries have relied on new studies and risk calculation method on whole life. In France, public health policy estimates that a health event risk target of less than $1 \%$ in life is acceptable. By respecting this consumption, it is estimated that people have less than $1 \%$ chance of developing alcohol-related pathologies such as cancer, diabetes, cardiovascular pathologies, or myocardial infarction [1].

For cardiovascular risks, the literature describes a dose-response relationship in $U$ or J curves [2]. In other words, a small consumption could reduce the cardiovascular risk, while the higher consumption leads to an increase in the prevalence of these pathologies. This ambiguous relationship could sometimes give a positive image of alcohol consumption.

For sailors, cardiovascular risk control is a priority [3, 4]. Because of the geographical distance, care is difficult and can be delayed. Cardiovascular pathologies would represent nearly one in five health emergencies on board ships. We know that alcohol consumption is important in this population. But we do not know exactly how to quantify this consumption. In a study of 136 Filipino sailors, $80 \%$ of the subjects had consumed alcohol at least once in the month [4]. Fort et al. [5] showed that $16 \%$ of the 1847 seafarers in their study were at risk of addiction. In other words, $16 \%$ of sailors had high consumption which also led to an increase in cardiovascular risk [5]. What about the remaining $84 \%$ ? In a recent literature review of mariners' cardiovascular risk factors, only one study considered alcohol consumption [4]. But alcohol consumption was assessed qualitatively, without quantifying consumption. As we have said, the dose-effect relationship for alcohol may be not linear. Quantifying consumption is therefore important for assessing cardiovascular risk.

Given the new scientific data and the importance of these pathologies in shipboard emergencies, it would seem useful to take alcohol consumption more into account in assessing cardiovascular risk. Any study of mariners' cardiovascular risk factors should quantify the consumption of alcohol in standard units per unit of time. Similarly, targeted prevention of cardiovascular risks in link with alcohol consumption would seem appropriate. This should be done in a program that takes into account other modifiable risk factors such as smoking, stress or organizations.

\section{REFERENCES}

1. Shield KD, Gmel G, Gmel G, et al. Life-time risk of mortality due to different levels of alcohol consumption in seven European countries: implications for low-risk drinking guidelines. Addiction. 2017; 112(9): 1535-1544, doi: 10.1111/add.13827, indexed in Pubmed: 28318072.

2. O'Keefe EL, DiNicolantonio JJ, O'Keefe JH, et al. Alcohol and CV Health: Jekyll and Hyde J-Curves. Prog Cardiovasc Dis. 2018; 61(1): 68-75, doi: 10.1016/j.pcad.2018.02.001, indexed in Pubmed: 29458056.

3. Oldenburg M. Risk of cardiovascular diseases in seafarers. Int Marit Health. 2014; 65(2): 53-57, doi: 10.5603/IMH.2014.0012, indexed in Pubmed: 25231325.

4. Szafran-Dobrowolska J, Renke M, Jeżewska M. Is it worth to continue to analyse the factors of cardiovascular risk among the sailors? Review of literature. Int Marit Health. 2019; 70(1): 17-21, doi: 10.5603/IMH.2019.0003, indexed in Pubmed: 30931513.

5. Fort E, Massardier-Pilonchery A, Bergeret A. Alcohol and nicotine dependence in French seafarers. Int Marit Health. 2009; 60(1-2): 18-28, indexed in Pubmed: 20205123. 